\title{
Clinical and neuropsychological assessment of attention and ADHD comorbidity in a sample of children and adolescents with idiopathic epilepsy
}

Avaliação clínica e neuropsicológica da atenção e comorbidade com TDAH em crianças e adolescentes com epilepsia idiopática

Celia Regina Carvalho Machado da Costa', Guilherme de Macêdo Oliveira², Marleide da Mota Gomes ${ }^{1}$, Heber de Souza Maia Filho ${ }^{3}$

\begin{abstract}
Children with epilepsy present significant problems concerning attention and comorbidity with attention deficit hyperactivity disorder (ADHD). Objective: To determine the prevalence of attention complaints, ADHD diagnosis and attention profile in a sample of children and adolescents with idiopathic epilepsy. Method: 36 children and adolescents with idiopathic epilepsy and 37 genre and age matched healthy controls underwent several procedures to diagnose their neuropsychological profile and comorbidity with ADHD. Results: The prevalence of ADHD was higher in patients with epilepsy $\left[\chi^{2}=4.1, p=0.043,6(16.7 \%)\right.$ vs $\left.1(2.7 \%)\right]$, with worse results in attention related WISC items and factors in patients with epilepsy comparing to the controls, but not between patients with and without ADHD. Clinical characteristics did not influence those results. Conclusion: This study found a greater prevalence of problems wih attention in pediatric patients with idiopathic epilepsy, but not a distinct profile between those with or without ADHD.
\end{abstract}

Keywords: epilepsy, attention, ADHD, childhood, adolescence.

\section{RESUMO}

Crianças com epilepsia podem apresentar problemas de atenção e comorbidade com transtorno de atenção e hiperatividade (TDAH). Objetivo: Determinar a prevalência de queixas de atenção, diagnóstico de TDAH e perfil atentivo em uma amostra de crianças e adolescentes com epilepsia idiopática. Método: 36 crianças e adolescentes com epilepsia idiopática e 37 controles saudáveis foram submetidos a vários procedimentos para diagnosticar perfil neuropsicológico e comorbidade com TDAH. Resultados: A prevalência de TDAH foi maior em pacientes com epilepsia $\left[\chi^{2}=4,1, p=0,043,6\right.$ ( 16,7\%) vs 1 (2,7\%)] , que também apresentaram piores resultados em itens e fatores dependentes de atenção do WISC. Não foram observadas diferenças entre pacientes com e sem TDAH. As características clínicas não influenciaram resultados. Conclusão: Este estudo encontrou uma maior prevalência de problemas com atenção em pacientes pediátricos com epilepsia idiopática, mas não um perfil distinto entre aqueles com ou sem TDAH.

Palavras-chave: epilepsia, atenção, TDAH, infância, adolescência.

Children and adolescents with epilepsy have more problems with attention, and therefore, more behavioral complaints and learning deficits ${ }^{1,2}$. In addition to epilepsy-related variables, many comorbidities contribute to attention deficits in this population, such as learning and psychiatric (mood and anxiety) disorders and attention deficit hyperactivity disorder (ADHD) ${ }^{1}$.
$\mathrm{ADHD}$ is the most prevalent neuropsychiatric disorder among children in school age (5\% in Brazilian sutides) $)^{3,4}$. The prevalence of ADHD is higher in children with epilepsy, ranging from $28.6 \%$ to $37.7 \%^{1,5,6}$. Some authors argue that this prevalence must be equal of the general population (3\%-5\%) when only patients with normal intelligence and controlled seizures were analyzed ${ }^{7}$. Even though, recent

\footnotetext{
${ }^{1}$ Universidade Federal do Rio de Janeiro, Departamento de Psiquiatria, Rio de Janeiro RJ, Brazil;

${ }^{2}$ Fundação Oswaldo Cruz, Rio de Janeiro RJ, Brazil;

${ }^{3}$ Universidade Federal Fluminense, Departamento de Neurologia, Niterói RJ, Brazil.

Correspondence: Heber Maia Filho; Universidade Federal Fluminense; Rua Marquês do Paraná, 303; 24030-210 Niterói RJ, Brasil; E-mail: hebersmf@gmail.com Conflict of interest: There is no conflict of interest to declare.

Received 22 February 2014; Received in final form 20 October 2014; Accepted 07 November 2014.
} 
population based studies supports the first hospital-based findings of a greater prevalence ${ }^{8}$. Inattention symptoms may indeed precede the diagnosis of epilepsy in some children'. Chou et al described a bidirectional association between ADHD and epilepsy in a longitudinal population based study, with greater hazard risks for ADHD in children with epilepsy and of epilepsy in those with ADHD during a 7,5 year follow-up ${ }^{10}$. Children with ADHD and epilepsy differ from other samples of children with ADHD for having equal gender prevalence and for having predominantly attention disorders rather than hyperactivity ones ${ }^{8,10}$. A Brazilian study reported a higher prevalence of hyperactivity symptoms ${ }^{11}$.

Studies involving attention problems in children with epilepsy show great heterogeneity ${ }^{1,5,6,12,13}$ concerning design, inclusion criteria, sample size, neuropsychological and clinical batteries, which interferes in drawing precise conclusions about the kind of relation between cognitive dysfunction and epilepsy: is it a predominant causal condition or is it a matter of comorbidity and similar neurobiological background? The study of a sample with normal intelligence and idiopathic epilepsy must favor the understanding of direct relationships between epilepsy and ADHD. It's also important to search for specific cognitive profile for these children, both aims of this cross sectional study. A broader approach to the children with well controled epilepsy must include a thorough behavioral and cognitive assessment, since problems in those areas may occur irrespective of seizure control status. Researches must address these questions in order to improve clinical decisions.

Our main research hypothesis to be tested were: there was higher prevalence of attention complaints and ADHD diagnosis in children and adolescents with epilepsy; the attention profile of patients with epilepsy is worse than controls; there is an association between clinical characteristics of epilepsy (disease duration, seizure frequency, type of seizure and polytherapy) and clinical complaints/attention profile; the attention profile and academic achievement of patients with epilepsy and ADHD were worse that those patients with epilepsy without this comorbidity.

\section{METHOD}

\section{Subjects}

Thirty six children of an original sample of 53 consecutively seen (February 2009 - February 2010) pediatric patients treated in the Pediatric Neurology clinic of the Hospital Universitário Antônio Pedro, located in the city of Niterói (Rio de Janeiro, Brazil), were selected according to the following criteria: having diagnosis of idiopathic epilepsy syndrome criteria $(1981,1989)^{14}$; formal testing of intellectual functioning (WISC III) with intelligence quocient (IQ) $>=80$; having normal clinical neurological examination and neuroimaging exams. The main reason for discarding 17 patients was IQ. The caregivers of children and adolescents with epilepsy were interviewed for informed consent and medical information concerning epilepsy. The seizure types were classified according to International League Against Epilepsy (ILAE) criteria ${ }^{14}$. Regarding the frequency of seizures, the patients were classified into three groups: no seizures (patients without any seizures in the last year), few seizures (patients with one to eleven seizures per year), and many seizures (patients with more than eleven attacks a year). Thirty seven healthy controls, matched in terms of age and gender were analyzed using the same clinical and neuropsychological batteries. Those controls had the same socioeconomical and cultural background (same region of habitation) and attended a nearby primary school. Their healthy status was assessed by a thorough clinical examination and interview with parentes by one of the authors (HSMF). The difference between the number of patients and controls is due to asymmetric losses because of low IQ.

There was no significant difference in the average age $(11.2 \pm 2.1$ vs. $11.4 \pm 2.1$ years), gender distribution (55.5\% vs. $64.9 \%$ males $)$ and level of education $(5.9 \pm 2.2$ vs. $6.1 \pm 2.3$ years of study) between patients and healthy controls. There was a significant difference between educational levels of caregivers, which were higher in the health control sample (9.3 \pm 4.3 vs. $12.1 \pm 3.9$ years of studying informed by them; $p=0.006)$. The duration of epilepsy ranged from 10 to 120 months, with an average of 49.1 months (standard deviation (SD) 27.2). Family history of epilepsy was negative in 27 patients (75\%). Twenty-three patients (63.9\%) had no seizures in the last year and 8 patients $(22.2 \%$ ) had a few seizures. Nineteen patients (52.8\%) had generalized seizures, 13 patients (35.3\%) had focal seizures and 4 patients (11.9\%) had more than one kind of seizure. Thirty-one patients (86.1\%) used only one antiepileptic drug (AED), 4 patients (11.1\%) used more than one AED and one patient (2.8\%) did not go under drug treatment.

\section{Assessment}

Cross sectional study. All the measures were done in two visits to the hospital with one week interval. Children and adolescents with epilepsy have undergone neuropsychological evaluation to determine intellectual level, attention profile and academic achievement. The tests used were Weschler Intelligence Scale for Children $3^{\text {rd }}$ edition - WISC-III ${ }^{15}$ (total IQ, verbal and performance IQ; processing speed and freedom from distractibility factors; age-corrected values of subtests of the folowwing subtests: Coding, Arithmetic, Symbol Search and Digit Spam), Raven's Progressive Matrices ${ }^{16}$ (RPM; raw scores), Sustained Attention Test (SAT; raw scores) ${ }^{17}$, TAVISIII - Test of Visual Attention $-3^{\text {rd }}$ Edition (raw scores) ${ }^{18}$ and School Performance Test - SPT ${ }^{19}$ (raw scores). The WISC-III 
consists of 13 subtests organized into two groups: verbal and performance IQ. The results of children in subtest results in three IQ scales (verbal IQ, performance IQ and total IQ) and four optional scores named index factors (processing speed, perceptual organization, freedoom from distractibility and verbal comprehension $)^{15}$. RPM is a test of non-verbal intelligence, with a strong influence of attention and executive functions ${ }^{16}$. SAT is a kind of cancellation test that analyzes sustained and selective attention. TAVIS-III is computerized Brazilian test that analyzes sustained, selective and alternating attention ${ }^{18}$. SPT provides an objective assessment of the essential abilities to school performance, more specifically, writing, arithmetics and reading, according to school age and Brazilian school policies ${ }^{19}$.

The clinical assessment of ADHD comorbidity has been carried out with both SNAP-IV ${ }^{20}$, which was filled by caregivers and teachers, and clinical interview with caregivers based on the DSM-IV criteria for ADHD. The neuropsychology team were blinded for the ADHD diagnosis.

\section{Data Analysis}

The Statistical Package for Social Sciences Release (SPSS 16.0) for Windows was used to analyze data. The demographic, clinical, neuropsychological assessment and school performance data were all presented in descriptive statistics. The hypothesis tests were made within the specific goals and selected according to the variable type in use, categorical, continuous and discrete quantity. Frequency distributions were used to describe qualitative data (dichotomous and polychotomous categorical).

The results of attention were analyzed in relation to clinical, intelligence and academic achievement data. Neuropsychological and academic data were compared between patients and controls and between patients with and without ADHD. The following non-parametric statistical tests were used (sample didn't pass the normalty hypothesis by the Kolmogorov-Smirnov test): Mann-Whitney, Kruskal-Wallis and Spearman ( $\mathrm{p}$-value lower than 0.05 is considered significant, reported for two-tailed test).

\section{RESULTS}

\section{Neuropsychological evaluation}

Table 1 describes data on IQ, WISC attention dependent subtests, nonverbal intelligence and academic performance of children and adolescentes with epilepsy and healthy controls. Children and adolescents with epilepsy have lower mean results of perfromance IQ, processing speed and freedom from distractibility factors and weighted points of Coding, Symbol Search and Digit Spam than healthy controls. Table 2 describes the results of SAT and TAVIS. There is no differences between groups for the results of these attention tests.

\section{Attention complaints and ADHD diagnosis}

Table 3 describes the average results of the SNAP-IV which have been filled by caregivers and teachers. Table 4 describes ADHD diagnosis. Among the six diagnosed cases of $\mathrm{ADHD}$ in patients with epilepsy, $3(50 \%)$ presented the inattentive subtype and $3(50 \%)$ presented the combined subtype. Patients with epilepsy and ADHD had focal or generalized seizures in equal proportions. There was no significant difference between patients with epilepsy with or without $\mathrm{ADHD}$ in relation to age, genre, level of education or epilepsy duration. The single case of $\mathrm{ADHD}$ in the control group presented the combined subtype.

\section{Comparing clinical data and neuropsychological profile}

There were no significant associations between clinical aspects of epilepsy (focal $\mathrm{x}$ generaized seizures, disease duration, seizure frequency and number of AED) and neuropsychological profile (IQ factors or subtests; attention), except for two: more seizures and difficulty in alternate attention; focal seizures and difficulty in sustained attention (reaction time $0.72 \pm 0.35$ vs. $0.53 \pm 0.26 ; p=0.04$ ).

\section{Comparing academic achievement and neuropsychological profile/ADHD diagnosis}

Table 5 shows comparisons of academic achievement and neuropsychological profile among patients with and

Table 1. WISC results and school performance of the samples.

\begin{tabular}{|c|c|c|c|}
\hline & Patients with epilepsy $n=36$ mean \pm SD & Healthy controls $n=37$ mean $\pm S D$ & $p^{*}$ \\
\hline Full scale IQ (FSIQ)** & $99 \pm 13.3$ & $105.6 \pm 14.9$ & 0.056 \\
\hline Verbal IQ $(V I Q) * \star$ & $103 \pm 13.7$ & $106.2 \pm 14.6$ & 0.274 \\
\hline 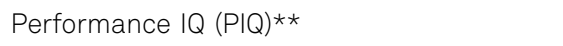 & $93.4 \pm 20.1$ & $104.1 \pm 15.5$ & 0.022 \\
\hline Processing speed factor (PSF)** & $89.9 \pm 14.7$ & $96.5 \pm 14.7$ & 0.020 \\
\hline Freedom from distractibility factor (FDF) ${ }^{\star \star}$ & $97.3 \pm 19.2$ & $104.9 \pm 18.1$ & 0.038 \\
\hline Coding & $7.8 \pm 3.4$ & $9.27 \pm 2.6$ & 0.027 \\
\hline Arithmetic & $9.1 \pm 3.8$ & $9.7 \pm 3.1$ & 0.30 \\
\hline Symbol search & $8.3 \pm 3.6$ & $10.1 \pm 3.5$ & 0.013 \\
\hline Digits & $10.3 \pm 3.7$ & $12.4 \pm 4.0$ & 0.013 \\
\hline Raven's Progressive Matrices (RPM) & $27.67 \pm 11.5$ & $28.4 \pm 6.2$ & 0.28 \\
\hline School performance test (SPT) & $97.4 \pm 33.6$ & $104.6 \pm 25$ & 0.6 \\
\hline
\end{tabular}

SD: Standard deviation; ${ }^{\star} p<0.05$ are shown in bold; ${ }^{\star}$ mean $100 \pm 20$; IQ: Intelligence quocient. 
Table 2. Results of attentional tests (mean and SD).

\begin{tabular}{|c|c|c|c|}
\hline & Patients with epilepsy $n=36$ mean \pm SD & Healthy controls $n=37$ mean $\pm S D$ & $\mathrm{p}$ \\
\hline SAT & $46.3 \pm 24.7$ & $48.5 \pm 18.6$ & 0.540 \\
\hline \multicolumn{4}{|l|}{ TAVIS } \\
\hline \multicolumn{4}{|c|}{ Selective attention } \\
\hline RT & $0.47 \pm 0.07$ & $0.51 \pm 0.18$ & 0.299 \\
\hline $\mathrm{NH}$ & $17.0 \pm 4.8$ & $17.8 \pm 8.9$ & 0.562 \\
\hline $\mathrm{OE}$ & $4.8 \pm 5.1$ & $4.51 \pm 4.7$ & 0.859 \\
\hline A & $11.5 \pm 8.8$ & $12.6 \pm 14.8$ & 0.814 \\
\hline \multicolumn{4}{|c|}{ Alternating attention } \\
\hline RT & $0.63 \pm 0.11$ & $0.59 \pm 0.18$ & 0.860 \\
\hline $\mathrm{NH}$ & $18.3 \pm 7.8$ & $16.5 \pm 5.1$ & 0.229 \\
\hline OE & $5.6 \pm 4.1$ & $5.1 \pm 5.5$ & 0.290 \\
\hline $\mathrm{AE}$ & $13.7 \pm 17.1$ & $8.35 \pm 7.4$ & 0.144 \\
\hline \multicolumn{4}{|c|}{ Sustained attention } \\
\hline RT & $0.61 \pm 0.31$ & $0.66 \pm 0.25$ & 0.244 \\
\hline $\mathrm{NH}$ & $49.6 \pm 15.4$ & $44.9 \pm 13.5$ & 0.232 \\
\hline OE & $2.81 \pm 10.9$ & $1.08 \pm 2.9$ & 0.897 \\
\hline $\mathrm{AE}$ & $8.6 \pm 23$ & $5.5 \pm 10.6$ & 0.540 \\
\hline
\end{tabular}

SD: Standard deviation; RT: Reaction time; NH: Number of hits; OE: Omission errors; AE: Action errors; SAT: Sustained attention test; TAVIS: Test of visual attention.

without ADHD. There were no significant differences except for two WISC items (Coding and Symbol Search). Because we found only one healthy control with ADHD we cannot test differences of the neuropschological among subgroups of cases and controls with or without ADHD.

\section{DISCUSSION}

The present study reveals that the prevalence of ADHD was higher in children and adolescents with epilepsy (16.7\%) than in controls (2.7\%), which was consistent with several studies found in literature. Although such consistency has been found, our results showed lower prevalence rates than the ones found in literature. Other studies dealed with more heterogenic or less seizure controlled samples of epilepsy, maybe leading to higher rate of attentional problems. Herman et al. ${ }^{6}$ found in their sample $31 \%$ of patients with ADHD compared to $6 \%$ of controls. The authors evaluated 75 children with newly diagnosed idiopathic epilepsy and found no association between attention deficits and clinical variables of epilepsy, similarly to the results found in this study. A Brazilian study, with a similar sample size $(\mathrm{n}=30)$ and no controls found a prevalence of $53.3 \%^{11}$. Cohen et al., in a population based study with 284,419 children found a prevalence of 5 out of 1,000 children, $27.7 \%$ of them also have epilepsy.

We found a similar distribution of combined and inattentive subtypes of ADHD, consistent with the previously mentioned authors, but different from the specific literature concerning ADHD, where there is a predominance of the combined subtype (2/3) in relation to the inattentive subtype ${ }^{3}$. In a smaller study with a prospective design, Bennett-Back et al. analyzed 40 children and their siblings, and also found a higher prevalence of ADHD in children with epilepsy ( $70 \%$ vs $16.7 \%$ ). They found more children with the inattentive subtype ${ }^{21}$. The greater prevalence of attentional problems must imply a clinical profile more prone to academic than behavioral problems and a greater need of scholar support. Vega et al..$^{13}$ are the ones to quote a higher prevalence of hyperactivity in samples with absence epilepsy. The scales of ADHD-related symptoms did not differ between samples on average. This may be related to the low total number of cases of ADHD in both samples. Kim et al. argued that this higher prevalence of ADHD diagnosis in children with epilepsy must be a bias of severe cases, finding a 6.9\% prevalence of ADHD in a sample of 102 children

Table 3. SNAP-IV scores.

\begin{tabular}{lccc}
\hline & Patients with epilepsy $n=36$ mean \pm SD & Healthy controls $n=37$ mean \pm SD & $p$ \\
\hline Inattention caregivers & $1.1 \pm 0.75$ & $1.4 \pm 0.73$ & 0.204 \\
Inattention teacher & $1.0 \pm 0.99$ & $1.2 \pm 0.80$ & 0.219 \\
Hyperactivity caregiver & $0.93 \pm 0.81$ & $0.96 \pm 0.80$ & 0.842 \\
Hyperactivity teacher & $0.93 \pm 1.93$ & $0.67 \pm 0.71$ & 0.434 \\
\hline
\end{tabular}

Cut-off points: inattention caregivers (1.78); Inattention teacher (2.56); Hyperactivity caregiver (1.44); Hyperactivity teacher (2.00). SD: Standard deviation; SNAP-IV: Swanson, Nolan e Pelham-IV questionnaire. 


\begin{tabular}{lccc}
\hline & With ADHD n (\%) & Without ADHD n (\%) & Total \\
\hline Patients with epilepsy & $6(16.7 \%)^{*}$ & $30(83.3 \%)$ & 36 \\
Healthy controls & $1(2.7 \%)^{* \star}$ & $36(97.3 \%)$ & 66 \\
Total & 7 & 37 \\
\hline$p=0.043 ; \chi^{2}=4.1 ; * 3$ combined and 3 inattentive subtype; **combined subtype. SD: Standard deviation; ADHD: Attention deficit hyperactivity disorder.
\end{tabular}

with normal intelligence and well controlled seizures ${ }^{7}$, but the previous mentioned studies were on benign cases. Our study endorses the overall tendency to find a higher prevalence of ADHD in this population, enrolling a similar population as Kim et al. ${ }^{7}$. Another Brazilian study ${ }^{11}$ sought an agreement regarding the completion of the scales for ADHD by parents and teachers of children with epilepsy. The scales filled by teachers are more negative for inattention, showing a greater number of symptoms of hyperactivity and impulsivity.
Another Brazilian study also found a predominance of hyperactivity symptoms ${ }^{11}$. Polanczyk et al., in a metanalysis about the prevalence of $\mathrm{ADHD}$ in general population affirms that the variation in the prevalence is more related to methodological characteristics of the various studies than to geographical diferences ${ }^{3}$, we can assume the same for variations in ADHD subtypes.

Due to the reduced sample used in this study, it was possible to compare only focal and generalized epilepsy, but not

Table 5. Comparison of intelligence, attention and academic achievement between patients with epilepsy with and without ADHD.

\begin{tabular}{|c|c|c|c|}
\hline & With ADHD $n=36$ & Without ADHD $n=37$ & $p^{*}$ \\
\hline Sustained Attention Test (SAT) & $42.2 \pm 35.1$ & $47.1 \pm 22.8$ & 0.797 \\
\hline 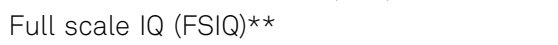 & $99 \pm 12.2$ & $99 \pm 13.7$ & 0.820 \\
\hline Verbal IQ $(\mathrm{VIQ})^{\star \star *}$ & $104.8 \pm 12.6$ & $102.6 \pm 14.4$ & 0.548 \\
\hline Performance IQ $(P I Q)^{\star \star}$ & $97.5 \pm 16.1$ & $92.6 \pm 20.9$ & 0.694 \\
\hline Processing speed factor (PSF)** & $82 \pm 14.7$ & $91.5 \pm 21$ & 0.268 \\
\hline Freedom from distractibility factor (FDF) ${ }^{\star \star}$ & $93.2 \pm 12.8$ & $98.1 \pm 20.4$ & 0.634 \\
\hline Raven’s Progressive Matrices (RPM) & $22.8 \pm 12.2$ & $28.9 \pm 11.2$ & 0.044 \\
\hline \multicolumn{4}{|l|}{ WISC subtests } \\
\hline Coding & $6.3 \pm 4.6$ & $8.1 \pm 3.1$ & 0.123 \\
\hline Arithmetics & $7.83 \pm 4.2$ & $9.4 \pm 3.8$ & 0.467 \\
\hline Symbol search & $7.67 \pm 1.0$ & $8.4 \pm 3.9$ & 0.650 \\
\hline Digit spam & $10.3 \pm 1.6$ & $10.4 \pm 4.0$ & 0.520 \\
\hline \multicolumn{4}{|l|}{ Selective attention } \\
\hline \multicolumn{4}{|l|}{ Alternating attention } \\
\hline $\mathrm{NH}$ & $0.49 \pm 0.04$ & $0.47 \pm 0.08$ & 0.372 \\
\hline OE & $17 \pm 1.8$ & $17 \pm 5.2$ & 0.635 \\
\hline$A E$ & $4.2 \pm 2.5$ & $4.9 \pm 5.5$ & 0.733 \\
\hline RT & $11.5 \pm 9.4$ & $11.6 \pm 8.8$ & 0.946 \\
\hline \multicolumn{4}{|l|}{ Sustained attention } \\
\hline $\mathrm{NH}$ & $0.63 \pm 0.11$ & $0.62 \pm 0.11$ & 0.910 \\
\hline OE & $22.5 \pm 16.2$ & $17.3 \pm 4.4$ & 0.874 \\
\hline$A E$ & $6 \pm 6.3$ & $5.5 \pm 3.6$ & 0.874 \\
\hline $\mathrm{RT}$ & $19.2 \pm 31.4$ & $12.5 \pm 12.8$ & 0.699 \\
\hline \multicolumn{4}{|l|}{ Selective attention } \\
\hline $\mathrm{NH}$ & $0.64 \pm 0.30$ & $0.6 \pm 0.32$ & 0.655 \\
\hline $\mathrm{OE}$ & $49.3 \pm 16.8$ & $49.7 \pm 15.4$ & 0.424 \\
\hline$A E$ & $2.5 \pm 5.17$ & $2.89 \pm 11.9$ & 0.241 \\
\hline $\mathrm{RT}$ & $29.8 \pm 51.5$ & $3.9 \pm 3.86$ & 0.548 \\
\hline \multicolumn{4}{|l|}{ School Performance Test (SPT) } \\
\hline Reading & 58.9 & 44.8 & 0.730 \\
\hline Writting & 23.6 & 19.0 & 0.780 \\
\hline Arithmetics & 18.4 & 15.6 & 0.697 \\
\hline Total & 101.0 & 79.5 & 0.882 \\
\hline
\end{tabular}

$\star_{p}<0.05$ are shown in bold; SD: Standard deviation; RT: Reaction time; NH: Number of hits; OE: Omission errors; AE: Action errors; ADHD: Attention deficit hyperactivity disorder. 
specific seizure subtypes or epileptic syndromes, with no differences in neuropsychological profile. Dafoulis et al. described less behavioral problems in benign focal epilepsy than generalized epilepsy ${ }^{22}$. Alonso et $\mathrm{al}^{23}$, found an association between attention and frequency of seizures in patients with focal seizures with impairment of consciouness/awareness. In this study, a worse alternate attention in TAVIS-III in patients with less controlled seizures could be found. Other authors found greater inattention in specific groups of idiopathic epilepsy, such as absence epilepsy ${ }^{12,13}$. For the same reason ( few patients in polytheraphy and high seizure frequency), we couldn't find any relation of the cognitive profile with these variables. Dafoulis et al. described worse behavior problems, including symptoms of ADHD in chronic idiopathic epilepsy, related to age of onset of epilepsy (later), number of antiepileptic drugs (polytherapy) and gender (male), but not seizure frequency or age ${ }^{22}$. Our results endorses the assumption that the absence of clinical variables of gravity must not preclude the clinician of a comprehensive search of cognitive problems in all patients with epilepsy.

Regarding demographic data, one should also mention that there was a higher level of education in healthy control caregivers, a difference of approximately three years. Despite this difference, we found no potential influences, once the academic achievement of the two samples was similar. We found no studies that investigate the influence of this factor on all samples of epilepsy, although the relation between a child's academic performance and the educational level of parents is known.

No significant differences between IQ of patients and controls were found, once this is a sample with idiopathic epilepsy where, by definition, there are no severe neurological deficits. However, there were lower scores on IQ factors and additional factors related to attention and executive functioning (performance IQ, processing speed and freedom from distractibility factors), as well as specific WISC-III subtests which are more dependent on attention (Coding, Symbol Search) and working memory (Digit Spam). The studies using the WISC (in its revised version, WISC-R, in the majority) have explored further full scale IQ than factors and subtests ${ }^{6}$. Alonso et al. describe compromise in the various subtests of the WISC-R for patients compared to controls ${ }^{23}$. It is, though, important to mention that they only analyzed epilepsy with focal seizures with impairment of consciouness (previously classified as focal complex). Hermann et al. ${ }^{6}$ analyzed the subtest Coding with a larger battery of executive functions, finding difficulties in patients with idiopathic epilepsy (there is no reference if generalized or focal). Again, the diversity of methods hinders a more accurate comparison of data found in the literature. In contrast, the specific assessment of attention showed no significant differences between patients and controls. Several studies have shown significant differences using various tests of attention, all with similar characteristics as the ones found in this study, evaluating visual attention in selective and sustained modalities. The best known test is CPT (Continuous Performance Test) used by Hermann et al. ${ }^{6}$. TAVIS III has a similar structure to CPT. On the other hand, the other tests used (SAT) are tests of cancellation, which also evaluate the selective and sustained attention ${ }^{17}$. TAVIS III also assesses alternating attention ${ }^{18}$. The use of raw scores and the small sample may hinder more accurate results on attention deficits.

When comparing patients with epilepsy in relation to neuropsychological variables and the diagnosis of ADHD, we found a significant difference only in the result of Raven's Progressive Matrices ${ }^{16}$ and two WISC items (Coding and Symbol Search), and a worse result for those with comorbidity. Raven's is a test of nonverbal intelligence with great dependence on attention, as well as visual perception ${ }^{5}$, as those two WISC items. Semrud-Clikeman et al. ${ }^{24}$, studiyng a diferente group patients with epilepsy (complex focal seizures), described that patients with epilepsy had worse results on tests of attention regardless of having comorbidity with ADHD, although this comorbidity was associated with worse outcomes. Other studies evaluate separately the prevalence of ADHD and neuropsychology of attention. Macallister et al. tried to describe specific neuropsychological endophenotypes for children with epilepsy with and with ADHD of both subtypes inattentive and combined. Those with ADHD and epilepsy have worse results of intellectual function, auditory attention and working memory. In a follow-up of the patients, the authors described the negative influence of seizure frequency and number of antiepileptic drugs on the results ${ }^{25}$. Bechtel et al. described that children with ADHD with or without epilepsy functions worse than health control in working memory tests, with no specific difference, with similar results in pharmacological response and functional neuroimaging, suggesting the view that $\mathrm{ADHD}$ with and without epilepsy shares a common underlying ${ }^{26}$. We know that many factors contribute to the results of neuropsychological tests, specially when it comes to epilepsy. In addition, the absence of neuropsychological evidence of deficits doesn't impedes the diagnosis of ADHD. Then, the absence of neuropsychological differences between the two groups is not contrary to the existence of comorbidity in this population. Furthermore, when dealing with people with lower income and social levels, other factors may influence the cognitive results. Our sample consisted of patients with epilepsy with little or no seizures of unknown etiology. It presented a distinct cognitive profile in some tests concerning attention and a higher prevalence of ADHD than controls. There has not been found any additional difference with ADHD comorbidity. As the potential effect of clinical variables of epilepsy on cognitive impairment is known ${ }^{27}$, one could postulate that these aspects should not be exclusive determinants of cognitive impairment in these patients. 
Dealing with a sample of tertiary care patients led to a more severe cognitive profile of the initial sample, with the exclusion of 14 patients because of low IQs. Our final sample, therefore, were of patients with less severe epilepsy. This precaution was important because the main objective of this study was to relate attention difficulties clinical aspects of epilepsy and comorbid ADHD, which would be jeopardized if we considered patients with lowered intellectual capacity. In a review of 2009, our group found nine studies on this topic ${ }^{28}$. Although all these studies selected patients without mental retardation (with the exception of Gonzalez-Heydrich et al. ${ }^{1}$, where almost $40 \%$ of the sample had IQ scores lower than 80), most researchers included children with very different etiologies (idiopathic, symptomatic and cryptogenic) and level of control of epileptic seizures, which limits the comparison of our data with the literature and generalization of results. The strict inclusion criteria in our sample aimed at reducing the range of possible cognitive and clinical interferences, but led to a small sample size, hindering the statistical significance appreciation of many findings. Kim et al. studied a similar population but of a greater sample size (102) although there are no data about neuropsychological function?

Other aspect that must be adressed is the possible comorbidities with other neuropsychiatric disorders other than ADHD in this sample. Another study of our group, analysing the same sample using the Child Behavior Checklist (CBCL) found worse results in psychopathology in children with epilepsy with certain psychopathological variables related to IQ (sluggish cognitive tempo, aggressive behavior, attention problem and activities) and academic performance (conduct, breaking rule behavior and school), also with no relation to clinical variables ${ }^{29}$.

The complexity of these relations and the multifactor nature of cognitive dysfunction in epilepsy seem to turn the implemented methodology (cross-sectional) too limited to confirm a causal relationship between attention deficit and epilepsy versus comorbid ADHD. However, it is considered an important endeavor to further investigate this question.

In conclusion, specific reasons for attention deficit in children with epilepsy are not clearly elucidated, but there is strong evidence that the problem exists and must be identified early. The results reinforce the importance of studying cognitive comorbidity in epilepsy and also clinical and neuropsychological analysis. That would allow the creation of cognitive and educational measures suited to this population, with the objective of improving their academic performance and thus their quality of life, minimizing the effects of a disease that can often be limiting, such as epilepsy.

\section{References}

1. Gonzalez-Heydrich J, Dodds A, Whitney J, MacMillan C, Waber D, Faraone SV et al. Psychiatric disorders and behavioral characteristics of pediatric patients with both epilepsy and attention-deficit hyperactivity disorder. Epilepsy Behav. 2007;10(3):384-8. http://dx. doi.org/10.1016/j.yebeh.2007.01.010

2. Aldenkamp AP, Weber B, Overweg-Plandsoen WC, Reijs R, Mil S. Educational underachievement in children with epilepsy: a model to predict the effects of epilepsy on educational achievement. J Child Neurol. 2005;20(3):175-80. http://dx.doi.org/10.1177/ 08830738050200030101

3. Polanczyk G, Lima MS, Horta BL, Biederman J, Rohde LA. The worldwide prevalence of ADHD: a systematic review and metaregression analysis. Am J Psychiatry. 2007;164(6):942-8. http://dx.doi. org/10.1176/appi.ajp.164.6.942

4. Rohde LA, Biederman J, Busnello EA, Zimmermann H, Schmitz M, Martins $S$ et al. ADHD in a school sample of Bra zilian adolescents: a study of prevalence, comorbid conditions, and impair ments. J Am Acad Child Adolesc Psychiatry. 1999;38(6):716-22. http://dx.doi.org/ 10.1097/00004583-199906000-00019

5. Dunn DW, Austin JK, Harezlak J, Ambrosius WT. ADHD and epilepsy in childhood. Dev Med Child Neurol. 2003;45(1):50-4. http://dx.doi.org/ 10.1111/j.1469-8749.2003.tb00859.x

6. Hermann B, Jones J, Dabbs K, Allen CA, Sheth R, Fine J et al. The frequency, complications and aetiology of ADHD in new onset paediatric epilepsy. Brain. 2007;130(12):3135-48. http://dx.doi.org/ 10.1093/brain/awm227

7. Kim GH, Kim JY, Byeon JH, Eun BL, Rhie YJ, Seo WH et al. Attention deficit hyperactivity disorder in epileptic children. J Korean Med Sci. 2012;27(10):1229-32. http://dx.doi.org/10.3346/jkms.2012.27.10.1229
8. Cohen R, Senecky Y, Shuper A, Inbar D, Chodick G, Shalev V et al. Prevalence of epilepsy and attention-deficit hyperactivity (ADHD) disorder: a population-based study. J Child Neurol. 2013;28(1):120-3. http://dx.doi.org/10.1177/0883073812440327

9. Hesdorffer DC, Ludvigsson P, Olafsson E, Gudmundsson G, Kjartansson O, Hauser WA et al. ADHD as a risk factor for incident unprovoked seizures and epilepsy in children. Arch Gen Psychiatry. 2004;61(7):731-36. http://dx.doi.org/10.1001/archpsyc.61.7.731

10. Chou IC, Chang YT, Chin ZN, Muo CH, Sung FC, Kuo HT et al. Correlation between epilepsy and attention deficit hyperactivity disorder: a population-based cohort study. PLoS ONE. 2013;8(3):e57926. http://dx.doi.org/10.1371/journal.pone.0057926

11. Loutfi KS, Carvalho AM, Lamounier JA, Nascimento JA. ADHD and epilepsy: contributions from the use of behavioral rating scales to investigate psychiatric comorbidities. Epilepsy Behav. 2011;20(3):484-9. http://dx.doi.org/10.1016/j.yebeh.2010.12.043

12. Caplan R, Siddarth P, Stahl L, Lanphier E, Vona P, Gurbani S et al. Childhood absence epilepsy: behavioral, cognitive, and linguistic comorbidities. Epilepsia. 2008;49(11):1838-46. http://dx.doi.org/ 10.1111/j.1528-1167.2008.01680.x

13. Vega C, Vestal M, DeSalvo M, Berman R, Chumg M, Blumenfeld H et al. Differentiation of attention-related problems in childhood absence epilepsy. Epilepsy Behav. 2010;19(1):82-5. http://dx.doi.org/ 10.1016/j.yebeh.2010.06.010

14. Berg AT, Berkovic SF, Brodie MJ, Buchhalter J, Cross JH, VaEmde Bas $W$ et al. Revised terminology and concepts for organization of seizures and epilepsies: report of the ILAE Commission on Classification and Terminology, 2005-2009. Epilepsia. 2010;51(4):676-85. http://dx.doi.org/10.1111/j.1528-1167.2010.02522.x 
15. Wechsler, DW. WISC III: escala de Inteligencia Wechsler para crianças: manual. 3a ed. São Paulo: Casa do Psicologo; 2002.

16. Raven, JC. Matrizes progressivas: escala geral. Rio de Janeiro: CEPA; 1997.

17. Cambraia SV. Atenção concentrada (AC): manual. São Paulo: Vetor; 2003.

18. Duchesne M, Mattos P. Normatização de um teste computadorizado de atenção visual. Arq Neuropsiquiatr. 1997;55(1):62-9.

19. Stein LM. TDE: Teste de desempenho escolar: manual para aplicação e interpretação. São Paulo: Casa do Psicólogo; 1994.

20. Mattos, P, Serra-Pinheiro MA, Rhode LA, Pinto D. Apresentação de uma versão em português para uso no Brasil do instrumento MTASNAP-IV de avaliação de sintomas de transtorno do déficit de atenção/hiperatividade e sintomas de transtorno desafiador e de oposição. Rev Psiquiatr Rio Gd Sul. 2006;28,(3):290-97. http://dx.doi. org/10.1590/S0101-81082006000300008

21. Bennett-Back O, Keren A, Zelnik N. Attention-deficit hyperactivity disorder in children with benign epilepsy and their siblings. Pediatr Neurol. 2011;44(3):187-92. http://dx.doi.org/10.1016/j.pediatrneurol. 2010.10.003

22. Dafoulis V, Kalyva E. Factors associated with behavioral problems in children with idiopathic epilepsy. Epilepsy Res. 2012;100(1-2):104-12. http://dx.doi.org/10.1016/j.eplepsyres.2012.01.014
23. Alonso-Pietro E, Álvarez MA, Reyes-Berazain A, Rojas-Massipe E, Romero-García C, Pando A. [Attention disorders in a sample of complex partial epileptic children]. Rev Neurol. 2001;33(10):991-3. Spanish.

24. Semrud-Clikeman M, Wical B. Components of attention in children with complex partial seizures with and without ADHD. Epilepsia. 1999;40(2):211-5. http://dx.doi.org/10.1111/j.1528-1157.1999.tb02077.x

25. MacAllister WS, Vasserman M, Vekaria P, Miles-Mason E, Hochsztein $\mathrm{N}$, Bender HA. Neuropsychological endophenotypes in ADHD with and without epilepsy. Appl Neuropsychol Child. 2012 Jul;1(2):121-8. http://dx.doi.org/10.1080/21622965.2012.709421

26. Bechtel N, Kobel M, Penner IK, Specht K, Klarhöfer M, Scheffler K, et al. Attention-deficit/hyperactivity disorder in childhood epilepsy: a neuropsychological and functional imaging study. Epilepsia. 2012;53(2):325-33. http://dx.doi.org/10.1111/j.1528-1167.2011.03377.x

27. Schubert R. Attention deficit disorder and epilepsy. Pediatr Neurol. 2005;32(1):1-10. http://dx.doi.org/10.1016/j.pediatrneurol.2004.06.007

28. Costa CRM, Maia Filho HS, Gomes MM. Epilepsia e saúde mental infantil. J Epilepsy Clin Neurophysiol. 2006;12(2):79-88. http://dx.doi. org/10.1590/S1676-26492006000300007

29. Moreira FS, Lima AB, Fonseca PC, Maia Filho HS. Mental health of children and adolescents with epilepsy: analysis of clinical and neuropsichological aspects. Arq Neuropsiquiatr. 2014;72(8):613-8. http://dx.doi.org/10.1590/0004-282X20140098 